\title{
PERAN KOMPETENSI PEDAGOGIK DAN PROFESIONAL TERHADAP KENERJA GURU EKONOMI
}

(The Role of Pedagogic and Professional Competency on The Performance of Economics Teachers)

\author{
Supriyanto*) \\ supriyanto@ulm.ac.id
}

*) Pendidikan Ekonomi Fakultas Keguruan dan Ilmu Pendidikan Universitas Lambung Mangkurat Banjarmasin

\begin{abstract}
This study aims at determining whether pedagogic competence and professional competence influence the performance of Economics teachers. For this purpose, a population of 23 teachers and 600 students was established, from which 23 teachers and 234 students were sampled. Data collection was by questionnaire for the pedagogical competence variable, while for professional competency variables and teacher performance was by observations made by researchers when the teachers were teaching. Data was analyzed using multiple linear regression analysis techniques. The results of the study show that pedagogic competency and professional competence simultaneously have a significant effect on the performance of Economics teachers, because the analysis indicated that $F_{\text {count }}>F_{\text {table. }}$ This can be seen from the figures of the $F_{\text {count }}$ which is equal to 31.404, while $F_{\text {table }}$ for dfn-k-1 $=20$ $($ sig $=0.05)$ which is 3.493. Since $R=0.871$ and $R 2=0.758$ at $p<0.01$, the indication is that the effect of pedagogic competence and professional competence on the performance of Economics teachers is very strong, because it is able to predict $75.8 \%$, while $24.2 \%$ is predicted by other variables outside of the scope of this research. Partially, the results of a simple correlation analysis between pedagogical competencies and performance of Economics teachers show that $r=0.815$ at $p<0.01$, indicating that pedagogic competence has a significant effect on the performance of Economics teachers. Likewise, professional competence and performance of Economics teachers show that $r=0.800$ at $p<0.01$, meaning that professional competence has a significant effect on teacher performance.
\end{abstract}

Keywords: Pedagogic Competence, Professional Competence, and Teacher Performance

\section{PENDAHULUAN}

Untuk meningkatkan mutu pendidikan guru dituntut agar bekerja secara profesional dan untuk itu guru harus memiliki kompetensi pedagogik yang memadai. Sementara hasil Uji Kompetensi Awal (UKA) pada tahun 2015 menunjukkan bahwa Guru di Propinsi Kalimanatan Selatan belum termasuk dalam peringkat 10 besar nasional (Kementrian Pendidikan dan Kebudayaan, 2017). Adapun jumlah guru SMA yang ada di Kabupaten Hulu Sungai Selatan (HSS) sebanyak 207 orang, dari jumlah tersebut guru yang sudah disertifikasi sebanyak 140 orang, sedangkan yang 67 orang masih belum tersertifkasi. Sedangkan di lingkungan MA dari jumlah guru yang sebanyak 169 orang, ternyata yang tersertifikasi baru sejumlah 66, adapun sisanya yang berjumah 103 belum tersertifikasi. Kenyataan seperti itulah yang kemungkinan menyebabkan tingkat kompetensi guru di lingkunagn propinsi Kalimantan selatan umumnya dan kabupaten HSS masih rendah.

Rendahnya kompetensi yang dimiliki dikhawatirkan akan mempengaruhi kinerja guru, hal ini sesuai dengan hasil penelitian Muh. Ilyas Ismail (2015) yang menunjukkan bahwa kinerja lebih berkonotasi pada sejauhmana seseorang melakukan aktivitas dan kewajibannya sesuai dengan kompetensi yang dikuasai. Sementara Sukaiesih (2012) dalam penelitiannya menemukan bahwa 
kinerja merupakan unjuk kerja guru dalam melaksanakan tugas dan kewajibannya yang berhubungan dengan penyusunan perencanaan, pelaksanaan pembelajaran, melakukan pembimbingan serta melakukan penelitian sederhana untuk kepentingan pembelajaran.Agar supaya guru bisa melakukan unjuk kerja secara maksimal, maka Jaka Permana (2008) dalam penelitiannya menyarankan kepada sekolah atau lembaga terkait untuk meningkatkan kualitas sumber daya guru agar mampu menghadapi tantangan dan persaingan yang semakin ketat. Hal ini sesuai dengan hasil penelitian Herman (2011) yang menunjukkan bahwa kompetensi guru mempunyai hubungan yang signifikan dengan kinerja guru di SMA se kota Makasar. Demikian juga hasil penelitian Eeng Ahman (2006) yang menunjukkan bahwa, persepsi terhadap pengembangan kompetensi professional mempunyai hubungan yang signifikan dengan kinerja pembelajaran guru. Hal yang serupa juga ditemukan oleh Marzuki Noor (2008) dalam penelitiannya menunjukkan bahwa terdapat pengaruh yang positif dan signifikan kompetensi terhadap kinerja guru. Temuan yang sama juga dikemukakan oleh Hartati (2012) dan M. Yudy Firdaus (2009).

Mengacu kepada fenomenafenomena yang terjadi di lingkungan Propinsi Kalimantan Selatan, khususnya Kabupaten HSS dan hasil-hasil penelitian terdahulu, maka penelitian ini bertujuan untuk mengetahui apakah kompetensi pedagogik dan kompetensi professional berpengaruh terhadap kinerja guru ekonomi di SLTA se-Kabupaten HSS.

\section{METODE PENELITIAN}

Penelitian ini merupakan penelitian ex post facto dengan pendekatan kuantitatif. Waktu peneltian selama 3 (tiga) bulan. Populasi penelitian sebesar 23 orang guru dan 600 orang siswa, sedangkan sampel peneltiannya adalah 23 orang guru dan 234 orang siswa. Teknik sampling yang digunakan adalah sampling acak berstrata mengacu pada tabel Krejcie Morgan dengan tingkat kesalahan 5\%.

Teknik pengumpulan data yang digunakan adalah angket (kuesioner) dan lembar obserasi. Angket digunakan untuk mengumpulkan data yang berkaitan dengan varibel kompetensi pedagogic. Adapun yang melakukan pengumpulan data adalah para siswa kelas X, XI dan XII yang diambil secara acak berstrata berjumlah 234 orang. Sedangkan lembar observasi digunakan untuk mengumpulkan data yang berkaitan dengan variabel kompetensi professional dan kinerja guru. Adapun yang melakukan pengumpulan data adalah peneliti yang mengapati guru pada saat melaksanakan tugas mengajar.

Teknik analisis yang digunakan dapat dipilah menjadi dua, yakni uji persyaratan analisis dan uji analisis. Uji persyaratan analisis meliputi : Uji normalitas, multikolinieritas, hiteokedastisitas, dan autokorelasi. Ini dilakukan dalam rangka untuk memastikan apakah teknik analisis yang digunakan memenuhi syarat. Uji analisis dilakukan dengan menggunakan regresi linier berganda. Teknis analisis ini dimasksudkan untuk menguji, baik secara simultan maupun parsial tentang pengaruh kompetensi pedagogis dan professional terhadap kinerja guru.

\section{HASIL PENELITIAN DAN PEMBAHASAN}

Hasil penlitian yang akan disampaikan meliputi hasil distribusi frekuensi dan hasil uji hipotesis penelitian. Hasil distribusi frekuensi meliputi kondisi kopentensi pedagogik, kompetensi professional dan kinerja guru ekonomi. Sedakang hasil uji hipotesis penelitian terdiri dari : pengaruh secara simultan dan parsial.

Hasil distribusi frekuensi terdiri dari : Pertama, Kondisi Kompetensi Pedagogik, berdasarkan hasil distribusi frekuensi skor kopetensi pedagogic termasuk kategori baik dengan rata-rata skor sebesar 105,22. Adapun yang diukur 
dalam variabel ini diwakili oleh indikator : pemahaman terhadap peserta didik, pengembangan kurikulum, pelaksanaan pembelajaran, pemanfaatan teknologi pembelajaran, berkomunikasi dengan peserta didik, evaluasi hasil belajar dan pengembangan potensi yang dimiliki peserta didik; Kedua, Kondisi Kompetensi Profesional, berdasarkan hasil distribusi frekuensi skor kopetensi prpfesonal termasuk kategori cukup dengan rata-rata skor sebesar 24,70. Adapun yang diukur dalam variabel ini diwakili oleh indicator: penguasaan materi pelajaran secara luas dan mendalami sesuai dengan standar isi program satuan pendidikan, penguasaan konsep, metode disiplin keilmuan, dan teknologi yang relevan; Ketiga, Kondisi kinerja Guru Ekonomi, berdasarkan hasil distribusi frekuensi skor kinerja guru ekonomi termasuk kategori sangat baik dengan rata-rata skor sebesar 73,61. Adapun yang diukur dalam variabel ini diwakili oleh indicator : aspek guru melaksanakan pembelajaran dan guru menilai hasil pembelajaran.

Hasil uji hipotesis penelitian menunjukkan bahwa "kompetensi pedagogic dan kompetensi profesional berpengaruh signifikan terhadap kinerja guru ekonomi di SLTA se-Kabupaten HSS, baik secara simultan maupun secara parsial : Secara Simultan, hasil uji regresi secara simultan dengan menggunakan program SPSS 18 For Windows menunjukkan, bahwa $F_{\text {hitung }}$ sebesar 31,404, sementara $F_{\text {tabel }} d b_{n-k-1}=20$ pada ts $=5 \%$ diperoleh nilai sebesar 3,493. Ini menunjukkan $F_{\text {hitung }}>F_{\text {tabel }}$ artinya kompetensi pedagogic dan kompetensi professional secara simultan berpengaruh signifikan terhadap kinerja guru ekonomi SLTA se- Kabupaten HSS. Tingkat diterminasi kompetensi pedagogic dan kompetensi professional terhadap kinerja guru ekonomi dapat dilihat dari perolehan harga $R=0,871$ pada $p<0,01$ dan $\mathrm{R}^{2}=0,785$ atau $75,8 \%$. Ini menunjukkan bahwa kompetensi pedagogic dan kompetensi professional mampu memprediksi kinerja guru ekonomi sebesar 75,8\%, sedangkan sisanya yang sebesar $24,2 \%$ diprediksi (dipengaruhi) oleh variabel lain yang tidak dimasukkan dalam model penelitian ini; Secara Parsial, Hasil analisis korelasi sederhana antara kompetansi pedagogic dengan kinerja guru ekonomi menunjukkan harga $\mathrm{r}=0,815$ pada $\mathrm{p}<$ 0,01. Hal ini menunjukkan bahwa kompetensi pedagogic mempunyai pengaruh yang sangat tinggi terhadap kinerja guru ekonomi. Selanjutnya harga $r$ yang bernilai positif mengandung arti bahwa semakin tinggi kompetensi pedagogic, maka akan semakin meningkat kinerja guru ekonomi. Hasil analisis korelasi sederhana antara kompetansi profesional dengan kinerja guru ekonomi menunjukkan harga $\mathrm{r}=0,800$ pada $\mathrm{p}<$ 0,01. Hal ini menunjukkan bahwa kompetensi profesional mempunyai pengaruh yang sangat tinggi terhadap kinerja guru ekonomi. Selanjutnya harga $r$ yang bernilai positif mengandung arti bahwa semakin tinggi kompetensi profesional, maka akan semakin meningkat kinerja guru ekonomi.

\section{KESIMPULAN}

1. Kondisi Kompetensi Pedagogik guru ekonomi termasuk kategori baik dengan rata-rata skor 105,22 . Kondisi Kompetansi Profesional guru ekonom termasuk kategori cukup dengan ratarata skor 24,70. Kondisi kinerja Guru Ekonomi termasuk kategori sangat baik dengan rata-rata skor sebesar 73,61 .

2. Kompetensi pedagogic dan kompetensi professional secara simultan berpengaruh signifikan terhadap kinerja guru ekonomi SLTA seKabupaten HSS. Hal tersebut dapah dilihat dari harga $F_{\text {hitung }}>F_{\text {tabel }}$, yaitu $F_{\text {hitung }}$ sebesar 31,404 dan $F_{\text {tabel }} \mathrm{db}_{\mathrm{n}-\mathrm{k}-1}$ $=20$ pada $\mathrm{ts}=5 \%$ diperoleh harga sebesar 3,493.

3. Kompetensi pedagogic mempunyai pengaruh yang sangat tinggi terhadap 
kinerja guru ekonomi. Hal itu dapat dilihat dari harga $\mathrm{r}=0,815$ pada $\mathrm{p}<$ 0,01 .

4. Kompetensi profesional mempunyai pengaruh yang sangat tinggi terhadap kinerja guru ekonomi. Hal tersebut dapat dilihat dari harga $r=0,800$ pada $\mathrm{p}<0,01$.

\section{REFERENSI}

Abdul Rahmat (2009). Thiks Teacher, Thiks Professional, MQS Publishing: BandungPersada: Jakarta

Anas Sudiyono (2009), Pengantar Statistik Pendidikan, PT. Raja Grafindo

Eeng Ahman dkk (2006), Pengembangan Kompetensi Profesional Dalam Meningkatkan Kinerja Pembelajaran Ekonomi. Jurnal Ekonomi Koperasi Vol. 1 No. 2 Fakultas Pendidikan Ilmu Pengetahuan Sosial. Universitas Pendidikan Indonesia,Bandung.Pp 217

Herman (2011) Hubnan Kompetensi dan Kinerja Guru Ekonomi SMA. Jurnal Ekonomi Bisnis TH. 16 No. 1. Makasar pp. 17-24

Jacob (2008), Guru Sebagai Peneliti Dalam Pendidikan Matematika Suatu Upaya Meningkatkan Kualitas Mengajar MIMBAR PENDIDIKAN Journa Pendidkan Vol. XXXII No. 1 Guru dan Tuntutan Profesuonal pp 59-676

Jaka Permana (2008), Penembangan Sumber Daya Guru Dalam Upaya Meningkatkan Daya Saing Bangsa Dalam Pembangunan Berkelanjutan
Melalui Penggunaan Metrik Kompetensi Guru Di SMK. Profitabilitas Jurnal Ilmiah Pendidikan Ekonomi Akuntansi Vol. 2 No 3 pp. 29-35

Kementrian Pendidikan Nasional Direktorat Jenderal Peningkatan Muru Pendidikan dan Tenaga Kependidikan (2010)Pembinaan dan Pengembangan Profesi Guru Buku 2 Pedoman Pelaksanaan Penilaian Kinerja Guru (PK Guru)

Marzuki Noor ((2008) Analisis Tentang Profesionalisme dan Kinerja Guru. Gaung Persada : Jakarta.

Muh. Ilyas Ismail (2010), Kinerja dan Kompetensi Guru dalam Pembelajaran Journal Lentera Pendidikan Vol 13 No. 1 pp 44-63

Oemar Hamalik (2003), Pendidikan Guru Berdasarkan Kompetensi. PT Bumu Aksara Jakarta

Pelingei Hasyim (2005), Persepsi Mahasiswa Tentang Kopetensi Mengajar Dosen PGSD FIK Universitas Negeri Makasar. Edukasi Journal Pemikiran dan Penilaian Pendidikan Edisi Februari Vol 6 No. 1 Makasar pp 68-76

Sukaesih. (2012). Pernanan Supervisi Kepala Sekolah Dalam Meningkatkan Kinerja Guru, Jurnal Kependidikan. Pp. 43-52, Diakses 4 Juli 2017

Suparwoto, dkk (2011)Evaluasi Kinerja Guru IPA SD, SMP, dan SMA Pasca Sertifikasi, Jurnal Pendidikan, Vol. 41, No. 1, pp.87-110. 